\title{
Newly identified Molecular Marker Compound in Some Nigerian oils.
}

\author{
S. Abrakasa
}

Department of Petroleum Geochemistry, School of Civil Engineering and Geosciences, Newcastle University, NE1 7RU. UK.

\begin{abstract}
The Kolo Creek E2.0 reservoir oils from the Nigerian Niger Delta region have been studied for molecular marker by characterisation using full scan GC-MS and GC-MS-MS transition from $412 \rightarrow 369$.

An existing molecular marker compound normally found in coals and lignites has been observed in some these oils. This molecular marker - Lupane, sustains the biogenic origin of these oils as terrigenous and it is very similar to Oleanane.
\end{abstract}

\section{INTRODUCTION}

Nigerian oils had been shown in earlier studies to possess terrigenous characteristics $^{1-3}$; because of the presence of a molecular marker compound known as Oleanane. It is a pentacyclic triterpane, and it is very obvious and positioned immediately before $\mathrm{C}_{30}$ hopane in the $\mathrm{m} / \mathrm{z}=$ 191 mass chromatogram. Oleanane has its origin from angiosperms; these are flowering plants, which first appeared on the Earth during the cretaceous, between 85 and 60 million years ago. The compounds derived from these plants are specially used to classify oils that were generated from organic matter that were deposited at that time. This classification also corresponds to oils derived from organic matter that were in deltaic environments. Explicitly the compounds can be use an indicator of geologic age, determination of depositional environ- ment and biogenic origin of oils.

Lupane is of the same origin as Oleanane but has not been demon- strated to occur in oils however, George et $\mathrm{al}^{4}$, had identified it together with Oleanane in oil but it occurs frequently in coals and lignites as indicated by Peters and Moldowan ${ }^{5}$. The inability to identify Lupane prior to recent times, could be attributed to the fact that Lupane and Oleanane co-elute on non-polar GC columns, which are normally used for routine molecular marker compound analysis ${ }^{6}$. Nytoft, et $\mathbf{a l}^{6}$, also demonstrated the first unambiguous proof of Lupane in oils. This study may probably record the first proof of Lupane in a Nigerian oil from the Niger Delta.

\section{EXPERIMENTALS}

\section{Samples studied}

Samples for this study are all crude oils. They are Tertiary in age and are from wells of the E2.0 Reservoir of the Kolo Creek oil field in the central Niger Delta of Nigeria. The samples were collected from the wellhead and are representative of the bulk $^{\mathbf{7 , 8}}$. The samples were collected in glass sample vials, labelled and stored.

\section{Fractionation of crude oils}

The fractionation of the crude oils by liquid column chromatography was done for the separation of saturated hydrocarbons for the GC, GC-MS analysis ${ }^{7}$, the procedure is as stated. The oils were measured $(60 \mathrm{mg})$ onto Alumina (2mg) (AnalaR grade, supplied by $\mathrm{BDH}$, England) in sample vials, unto that, 5 drops of Dichloromethane (DCM) (AnalaR Grade, supplied by BDH, England), were added to blend the oil and the alumina for introduction of the samples. The standard glass columns $50 \mathrm{~cm}$ in length, $0.5 \mathrm{~cm}$ internal diameter were rinsed with DCM (10 $\mathrm{ml}$ ) and later with $10 \mathrm{ml}$ of Light Petroleum Spirit $\left(30^{\circ}-40^{\circ}\right)$, (Pet Ether) (AnalaR grade $\mathrm{BDH}$, England). The columns were then 
plugged with extracted cotton to serve as a pad on which the stationary phase silica gel 60, 0.063-0.2 mm (70-230) mesh, $\left(\mathrm{SiO}_{2}\right)$ (AnalaR grade, BDH, England) will rest. The columns were filled with Pet ether, followed by the introduction of the stationary phase $\left(\mathrm{SiO}_{2}\right), 2 \mathrm{~g}$ of Alumina was then added to keep the surface stable. The oil samples were introduced and then another $2 \mathrm{~g}$ of Alumina was added to avoid turbulence of the surface when introducing the eluent. The aliphatic fraction was obtained by eluting with $70 \mathrm{ml}$ Pet ether. The fraction was evaporated with a rotary evaporator and reduced under a nitrogen gas stream in a pre weighed sample vial. The saturated hydrocarbons were diluted with DCM $(1 \mathrm{mg}$ per $100 \mu \mathrm{l}$ of DCM) in a chromatographic vial for GC-MS-MS analysis.

\section{GC- MS - MS analysis}

The GCMS analysis of the aliphatic compounds was performed on the Varian CP3800 GC split/splitless injector $\left(280{ }^{\circ} \mathrm{C}\right)$ linked to a Varian 1200 Triple Quadrupole mass spectrometer (electron voltage $70 \mathrm{eV}$, filament current $80 \mathrm{uA}$, source temperature $230{ }^{\circ} \mathrm{C}$, quad temperature $40{ }^{\circ} \mathrm{C}$, multiplier voltage $1500 \mathrm{~V}$, interface temperature 300 $\left.{ }^{\circ} \mathrm{C}\right)$. The acquisition was controlled by a Dell GX150 computer (Varian Software).

Acquired in MS/MS (mrm) mode, 3 parent/daughter transitions were monitored using Argon as the collision gas at a pressure of $2 \mathrm{mT}$ Torr with collision energy of $-10 \mathrm{eV}$. The transitions were $412 \rightarrow 191,412$ $\rightarrow 274$ and $412 \rightarrow 369$.

The sample $(1 \mu \mathrm{l})$ in DCM was injected by Varian CP8400 auto sampler and split open after $1 \mathrm{~min}$ after the solvent peak had passed the GC temperature programme and data acquisition commenced. Separation was performed on a fused silica capillary column $(30 \mathrm{~m} \times 0.25 \mathrm{~mm}$ i.d.) coated with $0.25 \mathrm{um}$ $5 \%$ phenyl methyl silicone (HP-5). The GC was temperature programmed over 3 ramps from $40{ }^{\circ} \mathrm{C}-300{ }^{\circ} \mathrm{C}$ and held at a final temperature or $20 \mathrm{~min}$ with Helium as the carrier gas (flow $1 \mathrm{ml} / \mathrm{min}$ initial pressure of $50 \mathrm{kPa}$, split at $30 \mathrm{ml} / \mathrm{min}$.

\section{RESULT AND DISCUSSION}

In the $m / z=191$, mass chromatogram of the oils on full scan mode, Oleanane was identified $^{\mathbf{2 , 6}}$, Before now, the biomarker guide by Peters and Moldowan, $1993^{5}$ described Lupane as an unidentified interfering compound showing a singlet peak in the MS - MS 412 $\rightarrow 369$ transition, however, Peters et $\mathrm{al}^{\mathbf{9}}$, has reported that Lupane is being indicated and identified in the MS - MS transition of $412 \rightarrow 369$ and in the mass chromatogram $\mathrm{m} / \mathrm{z}=369$ from a fullscan. The mass spectra of synthetic Oleanane and Lupane are used as references. The differences observed from the mass spectra is the presence of the 369 fragment ion in Lupane, which is absent in the mass spectra of Oleanane. The peak heights for the 123 and 231 fragment ions in the mass spectra are higher for Lupane than Oleanane $^{6}$.The MS - MS transition of $412 \rightarrow 191,412 \rightarrow 274$ and $412 \rightarrow 369$ shows a clear difference in the elution times. From the MS - MS transition mass chromatogram, the elution time for Oleanane in the $412 \rightarrow 274$ transition is 40.636mins while the elution time for Lupane in the $412 \rightarrow 369$ transition is 40.644mins and $\mathrm{C}_{30}$ hopane elutes at $40.850 \mathrm{mins}$, there is a significant baseline separation. The slight difference in the elution times indicates the possibility of co-elution, which may be almost impossible to resolve on normal non-polar GC columns commonly used for GC-MS analysis ${ }^{\mathbf{6}} ;{ }^{9}$. Lupane elutes later probably because of the additional propyl side chain in its structure which is absent in Oleanane. 
Ion 191.00 (190.70 to 191.70): SA29PE.D

1600

1400

1200

1000

800

$6063.06 \quad 64.4064 .8965 .41$

$40 \mathrm{H}$

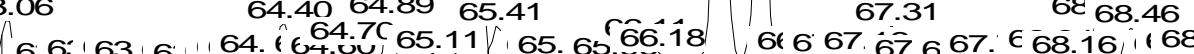
63.5064 OO $64.5065 .0065 .50 \quad 66.00 \quad 66.50 \quad 67.0067 .5068 .00 \quad 68.50$

$6 € 66.69$

65.32

Time-->

Abundance

Ion 274.00 (273.70 to 274.70): SA29PE.D

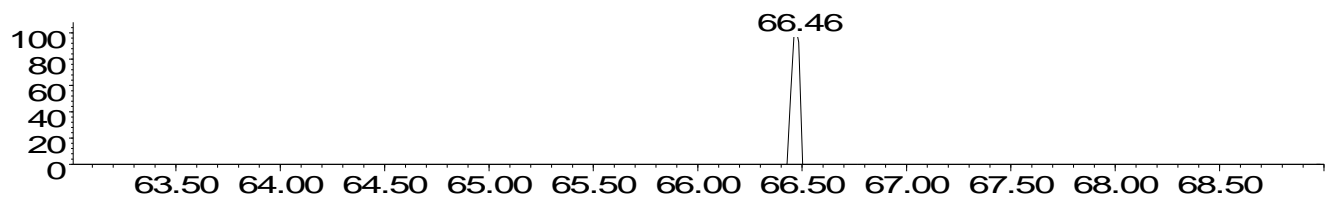

Time-->

Abundance

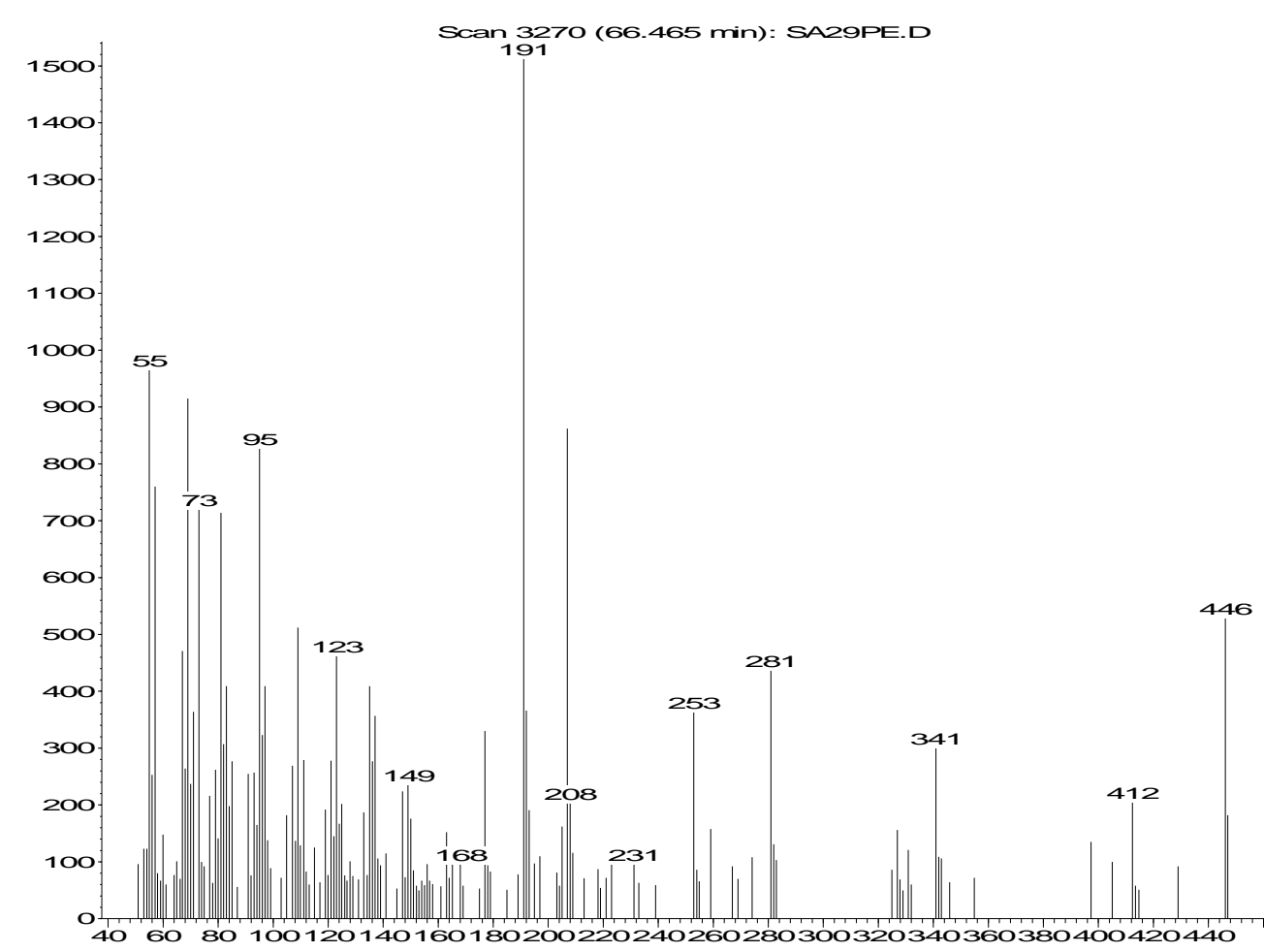

$m z-->$

Figure 1. : Mass chromatogram of $\mathrm{m} / \mathrm{z}=191, \mathrm{~m} / \mathrm{z}=274$ identifying Oleanane and mass spectra of Oleanane from Nigerian Niger Delta oil. 

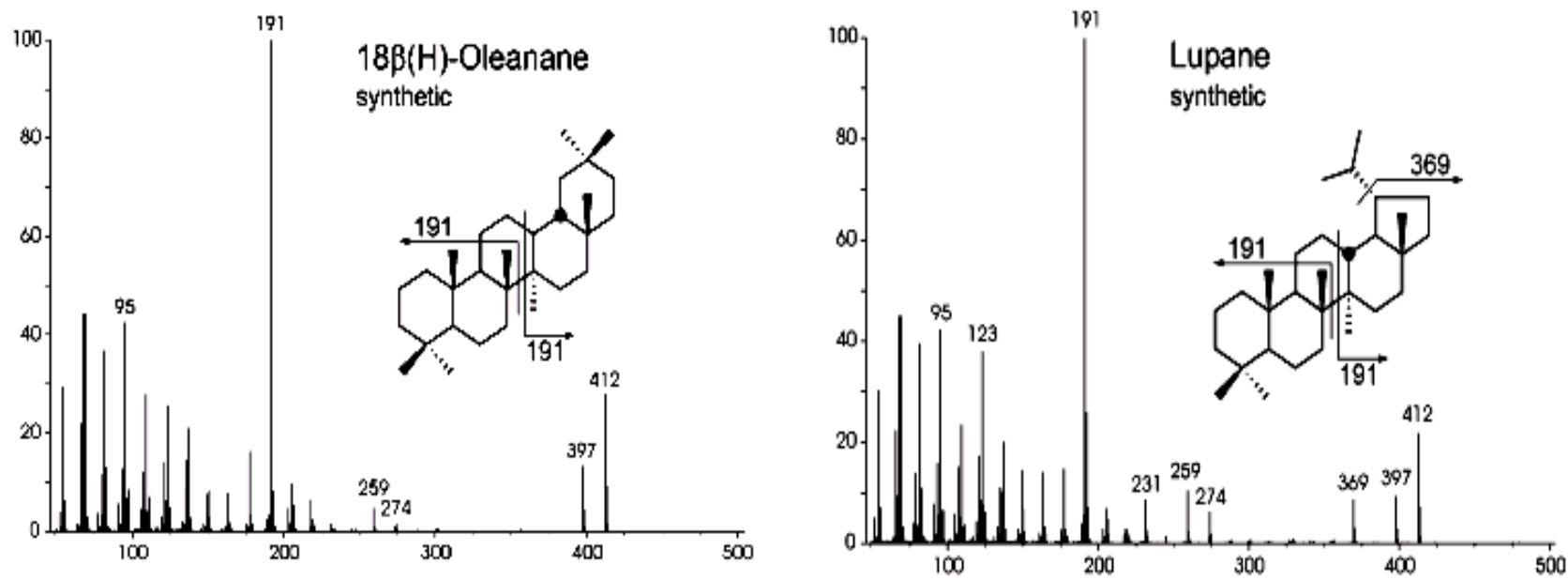

Figure 2. : Mass spectra of synthetic Oleanane and Lupane

Abundance

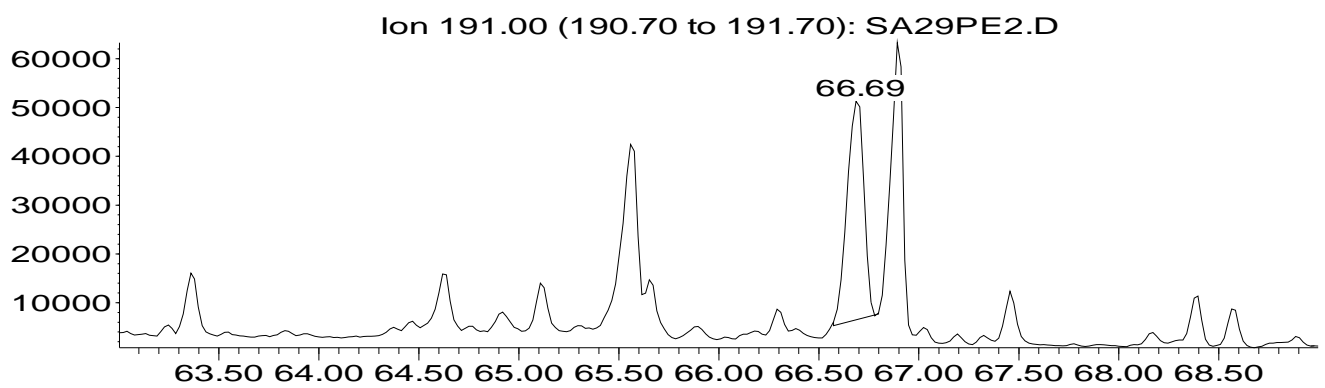

Time-->

Abundance

Ion 369.00 (368.70 to 369.70): SA29PE2.D

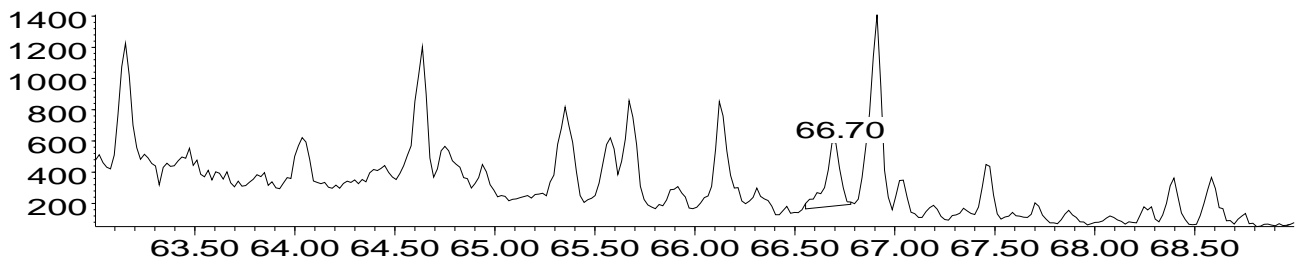

Time-->

Figure 3. : Mass chromatogram $m / z=191, m / z=369$ identifying Lupane and mass spectra of Lupane 


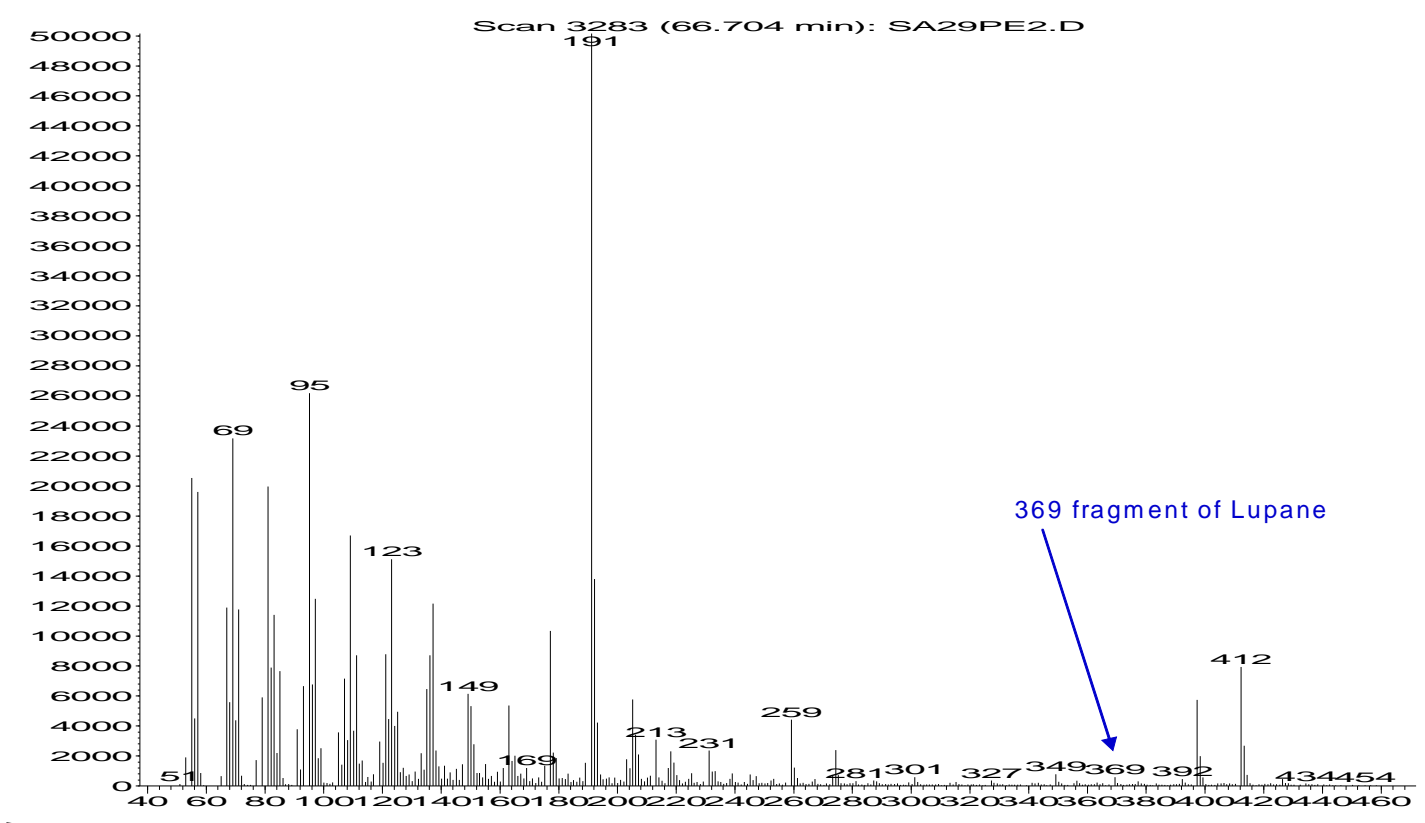

Mass spectra of Lupane in Nigerian oil

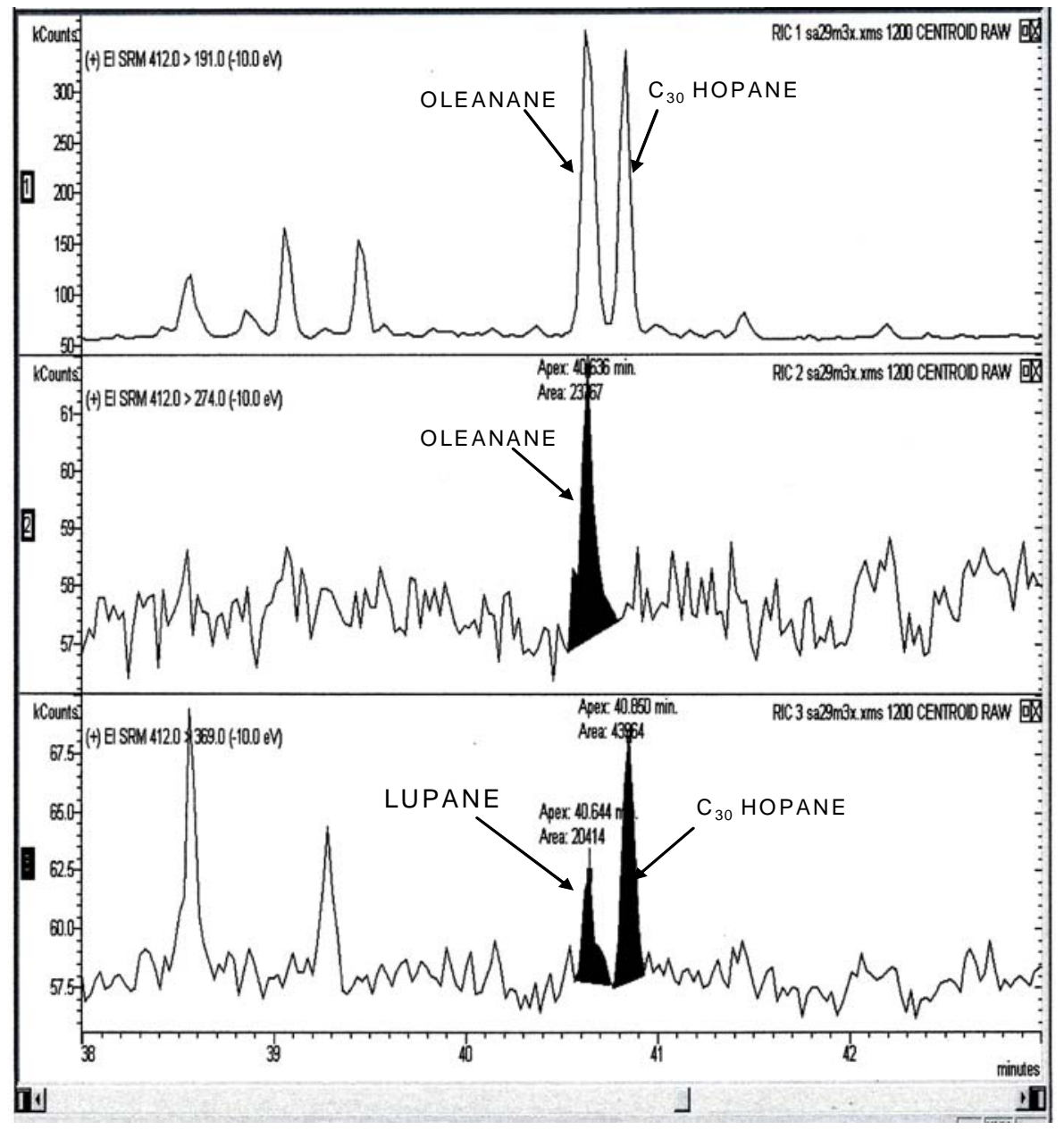

Figure 4: MS-MS transition of $412 \rightarrow 191,412 \rightarrow 274$ and $412 \rightarrow 369$ for identification of Oleanane (274) and Lupane (369). 


\section{CONCLUSION}

The mass chromatogram of the $\mathrm{m} / \mathrm{z}=191$ and $\mathrm{m} / \mathrm{z}=274$ identified Oleanane, since Lupane could not be identified in the $\mathrm{m} / \mathrm{z}=$ 191 , the MS - MS transition of $412 \rightarrow 369$ reveals the compound with an appreciable peak area and a significant baseline separation. The mass spectra of Lupane compared to that of the synthetic compound are similar confirming the compound. From this study, it is pertinent that whenever Oleanane is identified in an oil analysis, a check should be done to confirm possible co-elution with Lupane by MS-MS transition of $412 \rightarrow 369$ or the use of a polar column be employed to obtain an appreciable base line resolution.

\section{ACKNOWLEDGMENTS}

The author wish to thank P. Donohoe for assistance in GC-MS-MS analysis, Petroleum Technology Development Fund, Nigeria and Newcastle University, UK for sponsorships.

\section{REFERENCES}

1. Ekweozor, C. M. and Telnæs, N., Org. Geochem, 16, (1990), $401-413$.

2. Ekweozor, C. M. and Udo, O. T., Org. Geochem, 13, (1988), $131-140$.
3. Ekweozor, C. M., Okogun, J.I., Ekong, D. E. U. \& Maxwell, J. R., Org. Geochem, 27, (1979) $11-28$.

4. George, S. C., Eadington, P. J., Lisk, M., Quezada, R. A. PESA Journal, $26,64-81$.

5. Peters, K. E. and Moldowan, J. M., (1995), Biomarker Guide, Interpreting molecular fossils in petroleum and Ancient sediments. Prentice Hall, New Jersey.

6. Nytoft, H. P., Bojesen - Koefoed J. A., Christiansen, F. G., Fowler, M. G., Org. Geochem. 33, (2002) 1225 1240 .

7. Http://www.geolabnor.no/services.

(Geolab Nor). 2004.

8. Http://www.oiltracers.com. (Oil Tracers). 2004.

9. Peters, K., Clifford, C., Moldowan, M., (2005), The Biomarker Guide, Vol. 2, Biomarker and Isotopes in Petroleum Exploration and Earth History, $2^{\text {nd }}$ ed., P. 1155, Cambridge University press, UK.

Received: 13/3/2006

Accepted: 2/12/2006 